\title{
The proof for new oral anticoagulants: clinical trial evidence
}

\author{
Menno V. Huisman
}

Received: 15 March 2011 / Accepted: 8 May 2011 /Published online: 19 May 2011

(C) The Author(s) 2011. This article is published with open access at Springerlink.com

\begin{abstract}
Introduction Patients undergoing elective total hip or total knee replacement surgery are at increased risk of venous thromboembolism in the post-operative period and are recommended to receive thromboprophylaxis for 10 35 days. Although several thromboprophylactic agents are available, these are associated with well-recognized limitations. For the low molecular weight heparins (LMWHs) such as enoxaparin, these limitations include parenteral administration, indirect mode of action, inability to inhibit clot-bound thrombin and association with complications such as heparin-induced thrombocytopenia. These limitations make post-operative thromboprophylaxis challenging. Several new oral anticoagulants are in the advanced stages of clinical development. These agents have been designed to target either thrombin (dabigatran etexilate) or factor Xa (rivaroxaban and apixaban), which are key coagulation cascade enzymes.

Methods and results This review will present the published phase III clinical trial evidence of the efficacy and safety of dabigatran etexilate, rivaroxaban and apixaban, compared with the LMWH enoxaparin for the prevention of venous thromboembolism in patients who have undergone elective total hip or total knee replacement surgery. All three agents have shown comparable or superior efficacy compared with the European dose regimen of enoxaparin (40 $\mathrm{mg}$ once
\end{abstract}

This review is based on an oral presentation given by MV Huisman at the satellite symposium entitled From Proof to Practice: Innovations in Total Hip and Total Knee Replacement, which was held during the 11th EFORT Congress, Madrid, Spain (2 June 2010).

M. V. Huisman $(\bowtie)$

Section of Vascular Medicine, Department of General Internal

Medicine, Room CI R-43, Leiden University Medical Center,

PO Box 9600, 2300 RC, Leiden, The Netherlands

e-mail: m.v.huisman@lumc.nl daily), and comparable rates of major bleeding events. Dabigatran etexilate and rivaroxaban are currently licensed for use following elective hip and knee replacement surgery in many countries, but no direct comparative data exist upon which to base the choice of agent.

Conclusion A thorough assessment of each individual patient's thromboembolic and bleeding risks should be the basis of selecting the agent in order to balance efficacy and safety.

Keywords Apixaban · Dabigatran etexilate · Oral anticoagulants · Orthopaedics · Rivaroxaban · Venous thromboembolism

\section{Introduction}

Orthopaedic surgery, such as total hip and total knee replacement surgery, is associated with an increased risk of life-threatening and morbidity-associated venous thromboembolism (VTE) during the peri- and post-operative periods. As a result, current evidence-based clinical guidelines recommend the administration of anticoagulants to patients undergoing orthopaedic surgery [1]. In particular, patients undergoing elective hip or knee arthroplasty are recommended to receive thromboprophylaxis for at least 10 days, with treatment being continued for up to 35 days [1].

\section{Limitations of the current anticoagulants used in hip and knee arthroplasty}

It is extremely important that patients continue to receive their thromboprophylactic treatment once they have been discharged from hospital; this can be a challenge because 
several of the currently available agents, particularly those used in Europe (e.g. the low molecular weight heparins, LMWHs, such as enoxaparin), are parenterally administered. Other limitations associated with LMWHs, such as their indirect mode of action, inability to inhibit clot-bound thrombin, and association with complications such as heparin-induced thrombocytopenia and osteoporosis, can have a negative impact on their long-term, post-operative use [2]. In addition, the oral vitamin $\mathrm{K}$ antagonists (VKAs) such as warfarin, which are widely used in North America in this setting, are associated with a number of limitations (e.g. slow onset and offset of action, narrow therapeutic window, multiple drug and food interactions, and an unpredictable anticoagulant effect requiring regular anticoagulant monitoring and dose adjustment) that make their long-term use very problematic.

\section{New oral anticoagulants}

There has been a clear need for novel oral anticoagulant agents for some time, and a number are being developed that target either one of two specific molecules within the coagulation cascade, thrombin and factor Xa [3]. Four agents are at the more advanced stages of clinical development. Dabigatran etexilate is a direct thrombin inhibitor that reversibly inhibits the active site of thrombin, which is a central player in the coagulation cascade converting fibrinogen to fibrin. Rivaroxaban, apixaban and edoxaban are all factor Xa inhibitors, which bind reversibly to the active site of factor Xa. Table 1 presents the pharmacokinetic profiles of these four novel anticoagulants [3]. The bioavailability of dabigatran etexilate is much lower than that of the other three agents, so a higher dose of this agent is required. All four agents are given as a fixed dose, and their anticoagulant effects are so predictable that they do not require routine coagulation monitoring. In total knee or hip replacement, dabigatran etexilate, rivaroxaban and edoxaban are all administered once daily, while apixaban is administered twice daily. Dabigatran etexilate is mainly cleared by the kidneys, so care must be exercised in patients with renal insufficiency (creatinine clearance, 30-50 $\mathrm{ml} / \mathrm{min}$ ) [4]. Compared with the VKAs, there are few drug interactions with these novel oral anticoagulants, although they do interact with (i) potent inhibitors of P-glycoprotein (all except apixaban) and (ii) potent inhibitors of the cytochrome P450 enzyme CYP3A4 (all except dabigatran etexilate) [3].

\section{Evidence of primary VTE prevention from clinical trials}

The remainder of this review will focus on the published evidence from the clinical trial programmes for dabigatran etexilate, rivaroxaban and apixaban, in terms of the evaluation of their efficacy and safety for the primary prevention of VTE in patients undergoing elective hip and knee replacement surgery.

\section{Dabigatran etexilate}

Three phase III clinical trials that form part of the REVOLUTION $^{\circledR}$ study programme undertaken by Boehringer Ingelheim have been completed and published on the efficacy and safety of dabigatran etexilate for the primary prevention of VTE following elective hip and knee replacement surgery [5-7]. The three clinical trials had identical non-inferiority study designs with a primary endpoint of a composite of total VTE (asymptomatic and symptomatic deep vein thromboses and non-fatal pulmonary embolism) and all-cause death during treatment. The

Table 1 Pharmacokinetic profiles of the new oral anticoagulant agents [3]

\begin{tabular}{lllll}
\hline Characteristic & Dabigatran etexilate & Rivaroxaban & Apixaban & Edoxaban \\
\hline Target & Thrombin & Factor Xa & Factor Xa & Factor Xa \\
Prodrug & Yes & No & No & No \\
Bioavailability (\%) & 6 & 80 & 60 & 50 \\
Dosing & Once daily & Once daily & Twice daily & Once daily \\
Half-life (h) & $12-17$ & $7-11$ & 12 & $9-11$ \\
Renal clearance (\%) & 80 & 66 & 25 & 35 \\
Routine coagulation monitoring & No & No & No & No \\
Drug interactions & Potent inhibitors & Potent inhibitors of CYP3A4 & Potent inhibitors & Potent inhibitors of CYP3A4 \\
& of P-glycoprotein & and P-glycoprotein & of CYP3A4 & and P-glycoprotein \\
\hline
\end{tabular}

Adapted from [3]

${ }^{\text {a }}$ Potent inhibitors of P-glycoprotein include quinidine. Weak inhibitors of P-glycoprotein include amiodarone. Potent inhibitors of CYP3A4 include azole anti-fungals, macrolide antibiotics and protease inhibitors. Potent inhibitors of both P-glycoprotein and CYP3A4 include azole antifungals and protease inhibitors 
primary safety outcome was the occurrence of bleeding during treatment. Major bleeding during the treatment period was defined as: clinically overt bleeding associated with $\geq 20 \mathrm{~g} / 1$ fall in haemoglobin; clinically overt bleeding leading to a transfusion of $\geq 2$ units of packed cells or whole blood; fatal, retroperitoneal, intracranial, intraocular or intraspinal bleeding and bleeding warranting treatment cessation or leading to reoperation. The definition of major bleeding was consistent with the Committee for Proprietary Medicinal Products [8]. It is important to note that the assessment of bleeding also included surgical site bleeds. All efficacy and safety outcomes were assessed by an independent, central adjudication committee.

The RE-NOVATE ${ }^{\circledR}$ I trial randomized 3,494 patients undergoing total hip replacement surgery to receive 28 35 days of either dabigatran etexilate, $220 \mathrm{mg}(n=1,157)$ or $150 \mathrm{mg}(n=1,174)$ once daily, or subcutaneous enoxaparin, $40 \mathrm{mg}(n=1,162)$ once daily [5]. The dose of enoxaparin was equivalent to that used routinely in the European Union (EU). The RE-MODEL ${ }^{\mathrm{TM}}$ trial randomized 2,101 patients undergoing total knee replacement surgery to receive 610 days of either dabigatran etexilate, $220 \mathrm{mg}(n=694)$ or $150 \mathrm{mg}(n=708)$ once daily, or subcutaneous enoxaparin, $40 \mathrm{mg}(n=699)$ once daily [6]. The third trial, REMOBILIZE ${ }^{\circledR}$, used the North American enoxaparin regimen of $30 \mathrm{mg}$ enoxaparin $(n=876)$ twice daily, compared with either dabigatran etexilate, $220 \mathrm{mg}(n=862)$ or $150 \mathrm{mg}(n=$ 877 ) once daily for $12-15$ days, in patients undergoing total knee replacement surgery [7]. The follow-up period for these trials was $12-14$ weeks.

In both the RE-NOVATE ${ }^{\circledR}$ I and RE-MODEL ${ }^{\mathrm{TM}}$ trials, dabigatran etexilate demonstrated non-inferiority with the EU dose of enoxaparin ( $40 \mathrm{mg}$ once daily) for the primary efficacy composite outcome of total VTE and all-cause mortality (Fig. 1) [5, 6]. In RE-NOVATE ${ }^{\circledR}$ I, 6.7\% (60/897) of the enoxaparin group, compared with $6.0 \%(53 / 880)$ of the dabigatran etexilate 220-mg group and $8.6 \%(75 / 874)$ of the dabigatran etexilate $150-\mathrm{mg}$ group, experienced a primary efficacy outcome event (Fig. 1a) [5]. Although the rates of the primary efficacy outcome were higher in the RE-MODEL ${ }^{\mathrm{TM}}$ trial, as expected for knee replacement surgery, there were no significant differences between the three groups: $37.7 \%(193 / 512)$ of the enoxaparin group compared with $36.4 \%(183 / 503)$ of the dabigatran etexilate $220-\mathrm{mg}$ group and $40.5 \%(213 / 526)$ of the dabigatran etexilate 150-mg group (Fig. 1b) [6].

In terms of safety, both the RE-NOVATE ${ }^{\circledR}$ I and REMODEL $^{\mathrm{TM}}$ trials demonstrated similar major bleeding rates for the two dabigatran etexilate groups and the enoxaparin group (Fig. 2) $[5,6]$. In RE-NOVATE ${ }^{\circledR}$ I, major bleeding occurred in $1.6 \%$ of the enoxaparin group, compared with $2.0 \%$ of the dabigatran etexilate $220-\mathrm{mg}$ group and $1.3 \%$ of the dabigatran etexilate 150-mg group (Fig. 2a) [5]. a

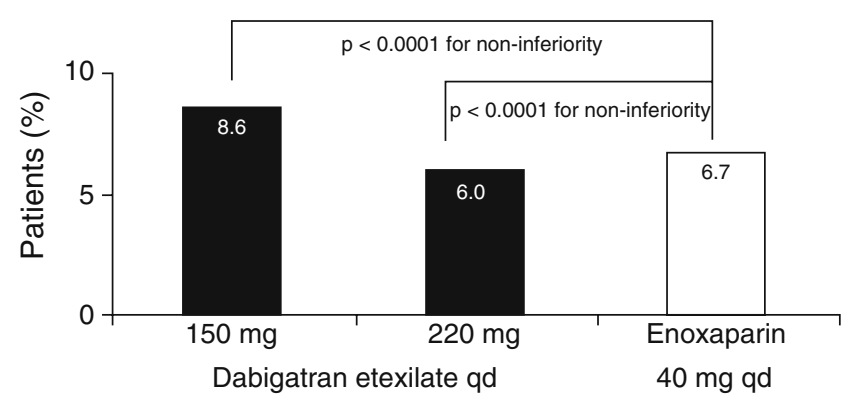

b

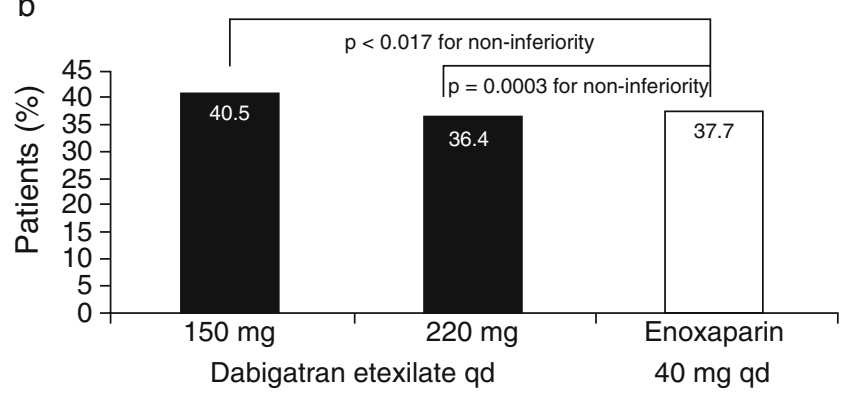

Fig. 1 Composite of total venous thromboembolic events (asymptomatic deep vein thrombosis and non-fatal pulmonary embolism) and all-cause mortality during treatment with either dabigatran etexilate, $150 \mathrm{mg}$ or $220 \mathrm{mg}$ once daily, or enoxaparin, $40 \mathrm{mg}$ once daily: $28-35$ days in RE-NOVATE ${ }^{\circledR}$ I $(n=3,494)($ a) and $6-10$ days in RE-MODEL TM $(n=2,076)$ (b) trials $[5,6]$

Similarly, in RE-MODELTM, major bleeding events occurred in $1.3 \%$ of the enoxaparin group, compared with $1.5 \%$ of the dabigatran etexilate $220-\mathrm{mg}$ group and $1.3 \%$ of the dabigatran etexilate 150-mg group (Fig. 2b) [6].

In the RE-MOBILIZE ${ }^{\circledR}$ trial, when dabigatran etexilate (220 $\mathrm{mg}$ and $150 \mathrm{mg}$ once daily) was compared with the North American dose of enoxaparin (30 mg twice daily), it was associated with numerically fewer major bleeding events, while it did not statistically achieve non-inferior efficacy, likely due to the $50 \%$ higher US dose of enoxaparin used in the study and the prolonged dosing regimen [7].

In summary, the three clinical trials described above demonstrated that dabigatran etexilate was as effective as the EU dose of enoxaparin ( $40 \mathrm{mg}$ once daily) at preventing VTE and all-cause mortality after total hip or total knee replacement surgery, but less effective than the North American dose of enoxaparin (30 mg twice daily) following knee arthroplasty. The safety profile of dabigatran etexilate was comparable with that of enoxaparin after either total hip or total knee replacement surgery. There were no significant differences between dabigatran etexilate and enoxaparin in terms of bleeding outcomes, the incidence of liver enzyme elevations (of particular relevance because of the problems experienced with another direct thrombin inhibitor, ximelagatran), and the incidence of acute coronary events either on or off therapy, which suggests there is 


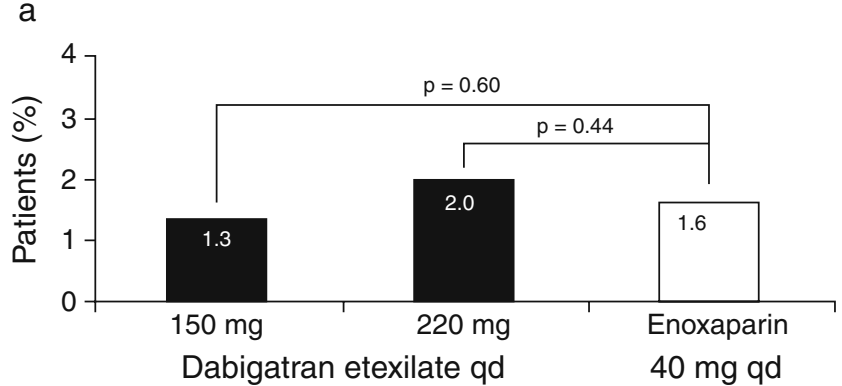

b

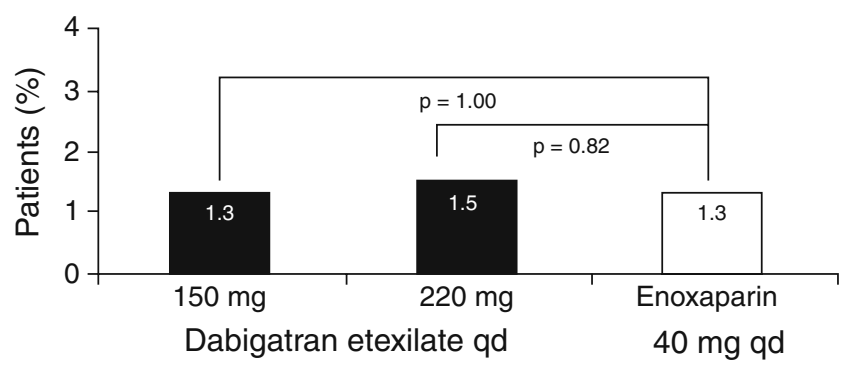

Fig. 2 Major bleeding events during treatment with either dabigatran etexilate, $150 \mathrm{mg}$ or $220 \mathrm{mg}$ once daily, or enoxaparin, $40 \mathrm{mg}$ once daily: $28-35$ days in RE-NOVATE ${ }^{\circledR} \mathrm{I}(n=3,494)$ (a) and $6-10$ days in RE-MODEL TM $(n=2,076)$ (b) trials [5, 6]. Major bleeding during the treatment period was defined as: clinically overt bleeding associated with $\geq 20 \mathrm{~g} / 1$ fall in haemoglobin; clinically overt leading to transfusion of $\geq 2$ units packed cells or whole blood; fatal, retroperitoneal, intracranial, intraocular or intraspinal bleeding and bleeding warranting treatment cessation or leading to reoperation

no rebound activation of coagulation with dabigatran etexilate [5-7]. A fourth, phase III clinical trial of dabigatran etexilate for the primary prevention of VTE following elective hip replacement surgery, RE-NOVATE ${ }^{\circledR}$ II (RE-NOVATE ${ }^{\circledR}$ II; ClinicalTrials.gov identifier: NCT00657150) [9], has recently been completed, and the results were reported at the 15th Congress of the European Hematology Association held in June 2010. In this double-blind, non-inferiority trial, patients $(n=2,055)$ undergoing total hip arthroplasty were randomized to receive either oral dabigatran etexilate, $220 \mathrm{mg}$ once daily, or subcutaneous enoxaparin, $40 \mathrm{mg}$ once daily, for 28 35 days [9]. Dabigatran etexilate demonstrated non-inferiority to enoxaparin for the primary efficacy outcome, a composite of total VTE and all-cause mortality, which occurred in $7.7 \%$ $(61 / 792)$ of the dabigatran etexilate group versus $8.8 \%$ (69/785) of the enoxaparin group [9]. Major bleeding rates were comparable in both groups and occurred in $1.4 \%$ of the dabigatran etexilate group and $0.9 \%$ of the enoxaparin group. Adverse events did not differ significantly between the two groups [9]. The study concluded that oral dabigatran etexilate, $220 \mathrm{mg}$ once daily, was as effective as subcutaneous enoxaparin, $40 \mathrm{mg}$ once daily, in reducing the VTE risk after total hip arthroplasty, with similar safety profiles and bleeding risk [9].
Rivaroxaban

As part of the RECORD clinical programme being undertaken by Bayer Schering Pharma AG, four phase III clinical trials have been completed and published on the efficacy and safety of rivaroxaban for the primary prevention of VTE following hip and knee arthroplasty [10-14] (Table 2). Of particular note is that the incidence of surgical site bleeding was not included in the bleeding data for the RECORD trials, which resulted in lower overall rates of bleeding compared with clinical trials of other thromboprophylactic agents such as dabigatran etexilate $[5,6]$.

The RECORD1 trial randomized 4,541 patients undergoing total hip replacement surgery to receive either rivaroxaban, $10 \mathrm{mg}(n=2,266)$ once daily, or subcutaneous enoxaparin, $40 \mathrm{mg}(n=2,275)$ once daily, for 35 days [10]. Significantly fewer patients in the rivaroxaban group $(1.1 \% ; 18 / 1,595)$ experienced a primary efficacy outcome event of deep vein thrombosis (symptomatic or venography-confirmed asymptomatic), non-fatal pulmonary embolism or death from any cause at 36 days, compared with patients in the enoxaparin group $(3.7 \% ; 58 / 1,558)$ (Table 2) [10]. There was no significant difference between the two groups in the rate of major bleeding $(0.3 \%$ for rivaroxaban versus $0.1 \%$ for enoxaparin) (Fig. 3) [10].

Similarly, the RECORD2 trial that was also undertaken in hip replacement patients $(n=2,509)$ demonstrated superior efficacy for rivaroxaban compared with enoxaparin for the same primary outcome composite, although it should be noted that rivaroxaban was administered for a longer period of time than enoxaparin (31-39 days versus 10-14 days, respectively) (Table 2) [11]. The major bleeding rates were identical for the two groups (0.08\%) (Fig. 3) [11].

Two studies, RECORD3 [12] and RECORD4 [13], were undertaken in patients undergoing total knee replacement surgery. RECORD3 randomized 2,531 patients to receive either rivaroxaban, $10 \mathrm{mg}(n=1,254)$ once daily, or subcutaneous enoxaparin, $40 \mathrm{mg}(n=1,277)$ once daily, for 10 14 days [12]. In contrast, RECORD4 compared rivaroxaban, $10 \mathrm{mg}(n=1,584)$ once daily, with the North American dose of enoxaparin (30 mg twice daily; $n=1,564$ ) [13]. Both studies demonstrated significantly fewer primary outcome events (VTE events and all-cause mortality) with rivaroxaban compared with enoxaparin (Table 2) and comparable rates of major bleeding (RECORD3: $0.6 \%$ versus $0.5 \%$, respectively; RECORD4: $0.7 \%$ versus $0.3 \%$, respectively) (Fig. 3) [12, 13].

In summary, once daily oral rivaroxaban $(10 \mathrm{mg})$ was significantly more effective than subcutaneous enoxaparin (both the EU and North American doses) at preventing VTE-related events after either elective hip or knee replacement surgery. There was no significant increase in the rate of major bleeding between rivaroxaban and enoxaparin, but surgical site bleeds were not included in 
Table 2 The main efficacy outcomes of the four RECORD trials in patients undergoing elective hip or knee arthroplasty [10-14]

\begin{tabular}{|c|c|c|c|c|c|c|}
\hline \multirow[t]{2}{*}{ Trial } & \multirow[t]{2}{*}{ Setting } & \multirow[t]{2}{*}{ Enoxaparin subcutaneous } & \multirow[t]{2}{*}{ Rivaroxaban oral } & \multicolumn{3}{|c|}{ Deep vein thrombosis/pulmonary embolism/death } \\
\hline & & & & Events $(\%)$ & Relative risk reduction $(\%)$ & $p$ value \\
\hline $\begin{array}{c}\text { RECORD1, } \\
n=4,541\end{array}$ & Total hip arthroplasty & $\begin{array}{l}40 \mathrm{mg} \text { once daily } \\
\text { for } 35 \text { days }\end{array}$ & $\begin{array}{l}10 \mathrm{mg} \text { once daily } \\
\text { for } 35 \text { days }\end{array}$ & 3.7 versus 1.1 & 70 & $<0.001$ \\
\hline $\begin{array}{c}\text { RECORD2, } \\
n=2,509\end{array}$ & Total hip arthroplasty & $\begin{array}{l}40 \mathrm{mg} \text { once daily } \\
\text { for } 10-14 \text { days }\end{array}$ & $\begin{array}{l}10 \mathrm{mg} \text { once daily } \\
\text { for } 31-39 \text { days }\end{array}$ & 9.3 versus 2.0 & 79 & $<0.0001$ \\
\hline $\begin{array}{c}\text { RECORD3, } \\
n=2,531\end{array}$ & Total knee arthroplasty & $\begin{array}{l}40 \mathrm{mg} \text { once daily } \\
\text { for } 10-14 \text { days }\end{array}$ & $\begin{array}{l}10 \mathrm{mg} \text { once daily } \\
\text { for } 10-14 \text { days }\end{array}$ & 18.9 versus 9.6 & 49 & $<0.001$ \\
\hline $\begin{array}{c}\text { RECORD4, } \\
n=3,148\end{array}$ & Total knee arthroplasty & $\begin{array}{l}30 \mathrm{mg} \text { twice daily } \\
\text { for } 10-14 \text { days }\end{array}$ & $\begin{array}{l}10 \mathrm{mg} \text { once daily } \\
\text { for } 10-14 \text { days }\end{array}$ & 10.1 versus 6.9 & 31 & 0.0160 \\
\hline
\end{tabular}

Adapted from [14] Copyright (2010), with permission from Elsevier

the safety outcome evaluation, and it is known from other studies that these contribute considerably to the total major bleeding rate $[5,6]$. Bleeding into the surgical site is of clinical importance to orthopaedic surgeons because of the negative impact it can have on the risk of wound infection and the need for reoperation of the prosthetic joint.

Apixaban

The ADVANCE clinical programme, which is being coordinated by Bristol-Myers Squibb and Pfizer, is evaluating the thromboprophylactic efficacy and safety of apixaban in a range of indications. Two phase III clinical trials that have been undertaken in orthopaedic patients have been published to date: the ADVANCE-1 and ADVANCE-2 studies in patients undergoing total knee replacement $[15,16]$. Similar to the dabigatran etexilate trials, these studies included bleeding at the surgical site in their safety analyses. The ADVANCE-1 study compared $10-14$ days of treatment with apixaban ( $2.5 \mathrm{mg}$ twice daily) with enoxaparin at the North American dose (30 mg twice daily) in 3,195 patients, and failed to show non-inferiority for apixaban for the composite primary efficacy outcome of total VTE events and all-cause mortality (Fig. 4a) [15]. This

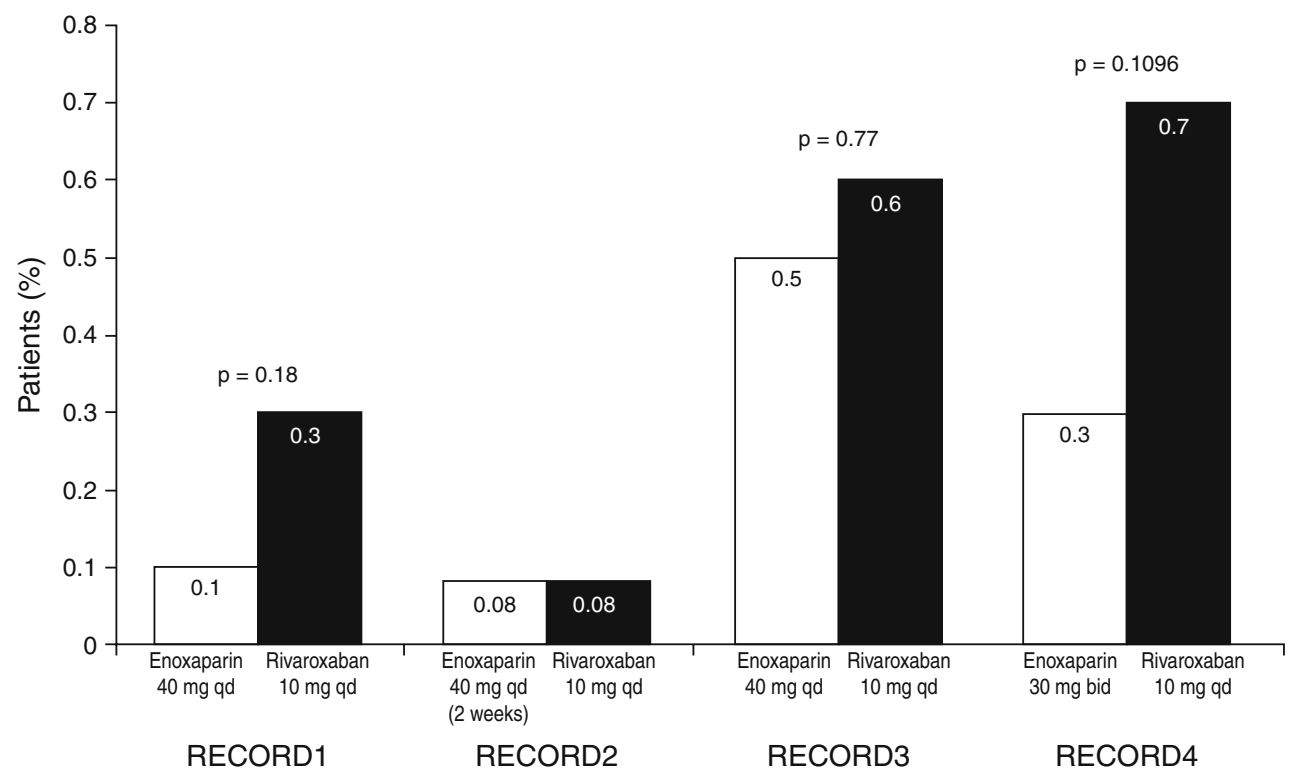

Fig. 3 Major bleeding events during treatment with either rivaroxaban, $10 \mathrm{mg}$ once daily, or enoxaparin, $40 \mathrm{mg}$ once daily, for 35 days in RECORD1 during total hip arthroplasty $(n=4,541)$; with either rivaroxaban, $10 \mathrm{mg}$ once daily for 31-39 days, or enoxaparin, $40 \mathrm{mg}$ once daily for 10-14 days, in RECORD2 during total hip arthroplasty $(n=2,509)$; with either rivaroxaban, $10 \mathrm{mg}$ once daily, or enoxaparin, $40 \mathrm{mg}$ once daily, for 10-14 days in RECORD3 during total knee arthroplasty $(n=2,531)$ and with either rivaroxaban, $10 \mathrm{mg}$ once daily,

or enoxaparin, $30 \mathrm{mg}$ twice daily, for 10-14 days in RECORD4 during total knee arthroplasty $(n=3,148)$. Major bleeding during the treatment period was defined as bleeding that was fatal, occurred in a critical organ (e.g. retroperitoneal, intracranial, intraocular or intraspinal bleeding), required reoperation or extra-surgical site bleeding that was clinically overt and was associated with a fall in haemoglobin level of at least $2 \mathrm{~g} / \mathrm{dl}$, or that required transfusion of $\geq 2$ units packed cells or whole blood [10-13] 
Fig. 4 Composite of any deep vein thrombosis, non-fatal pulmonary embolism and allcause mortality during treatment with either apixaban, $2.5 \mathrm{mg}$ twice daily, or enoxaparin, $30 \mathrm{mg}$ twice daily, for 10 14 days in the ADVANCE-1 study $(n=3,195)$ during total knee arthroplasty (a); and with either apixaban, $2.5 \mathrm{mg}$ twice daily, or enoxaparin, $40 \mathrm{mg}$ once daily, for 10-14 days in the ADVANCE-2 study $(n=3,057)$ during total knee arthroplasty (b) $[15,16]$ a

ADVANCE-1

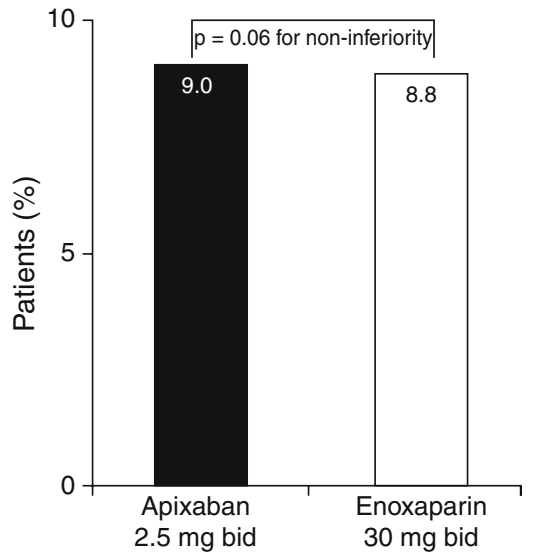

b

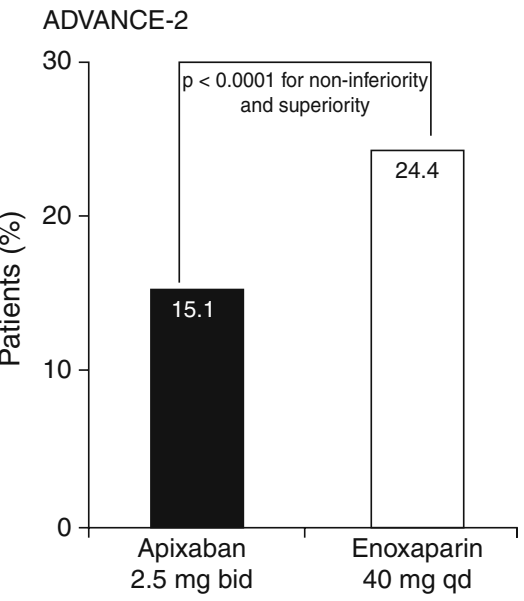

was because the incidence of the composite primary efficacy outcome in patients treated with enoxaparin was only $55 \%$ of the predicted rate that was used to establish the criteria for non-inferiority and to calculate the sample size [12]. Apixaban treatment was associated with fewer major bleeding events than enoxaparin $(0.7 \%$ versus $1.4 \%$, respectively) (Fig. 5a) [15]. In contrast, the subsequent ADVANCE-2 study in 3,057 patients demonstrated superior efficacy for apixaban (2.5 mg twice daily) compared with enoxaparin used at the EU dose (40 mg once daily) for the same primary efficacy composite outcome $(15.1 \%$ versus 24.4\%, respectively) (Fig. 4b) [16]. In addition, there was no significant difference in the rate of major bleeding (apixaban, 0.6\%; enoxaparin, 0.9\%) (Fig. 5b) and the rate of the composite of major bleeding and clinically relevant non-major bleeding between the two treatment groups (apixaban, 3.5\%; enoxaparin, 4.8\%) [16].

a

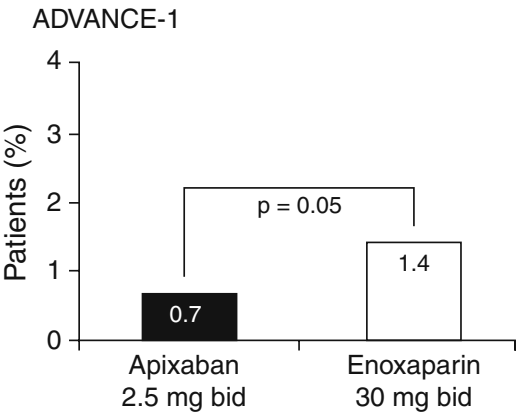

Fig. 5 Major bleeding events during treatment with either apixaban, $2.5 \mathrm{mg}$ twice daily, or enoxaparin, $30 \mathrm{mg}$ twice daily, for 10-14 days in the ADVANCE- 1 study $(n=3,195)$ during total knee arthroplasty (a); and with either apixaban, $2.5 \mathrm{mg}$ twice daily, or enoxaparin, $40 \mathrm{mg}$ once daily, for 10-14 days in the ADVANCE-2 study $(n=$ $3,057)$ during total knee arthroplasty (b). Major bleeding was defined as acute, clinically overt bleeding accompanied by one or more of the
In summary, apixaban demonstrated superiority compared with the EU dose of enoxaparin (40 mg once daily) but failed to show non-inferiority compared with the North American dose of enoxaparin $(30 \mathrm{mg}$ twice daily) for the prevention of VTE following total knee replacement surgery $[15,16]$. In terms of the incidence of major bleeding, apixaban demonstrated rates that were comparable with both enoxaparin dosing regimens.

\section{Treatment choice}

Of the new oral anticoagulants, dabigatran etexilate and rivaroxaban have been approved for use in patients following hip and knee replacement surgery in many countries. No direct head-to-head comparisons of these two agents have been made. However, a meta-analysis of

b

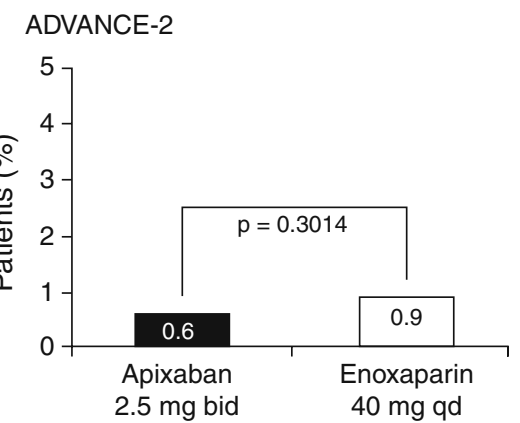

following events: a decrease in the haemoglobin level of $2 \mathrm{~g} / \mathrm{dl}$ or more within a 24 -h period; a transfusion of $\geq 2$ or more units of packed red cells; bleeding at a critical site (i.e. intracranial, intraspinal, intraocular, pericardial or retroperitoneal bleeding); bleeding into the operated joint, requiring an additional operation or intervention; intramuscular bleeding with the compartment syndrome or fatal bleeding $[15,16]$ 
the pivotal studies comparing dabigatran etexilate with enoxaparin $(n=8,185)$ or rivaroxaban with enoxaparin $(n=$ 10,220 ) for VTE prevention after total hip and total knee replacement surgery was undertaken using standardized bleeding definitions for major, plus clinically relevant nonmajor, bleeding [17]. This post hoc analysis demonstrated that dabigatran etexilate showed similar rates of efficacy and bleeding compared with enoxaparin (symptomatic VTE or death, $1.1 \%$ versus $0.9 \%$, respectively; major plus clinically relevant non-major bleeding, 5.6\% versus $5.0 \%$, respectively), while rivaroxaban was more effective than enoxaparin but had a significantly higher risk of bleeding (symptomatic VTE or all-cause mortality, $0.6 \%$ versus $1.2 \%$, respectively, $p<0.001$ for the odds ratio; major plus clinically relevant non-major bleeding, $3.1 \%$ versus $2.5 \%$, respectively, $p=0.049$ for the odds ratio) [17].

\section{Conclusions}

Three new oral anticoagulant agents have been evaluated in phase III clinical trials for VTE prevention in elective hip and knee replacement surgery compared with the LMWH enoxaparin administered subcutaneously, and the results have been published. Dabigatran etexilate, a direct thrombin inhibitor, at doses of 220 or $150 \mathrm{mg}$ once daily, has been shown to be as effective and safe as the EU dose of enoxaparin (40 mg once daily) and less effective, but equally safe, as the North American dose regimen of enoxaparin (30 mg twice daily). The factor Xa inhibitor rivaroxaban (10 $\mathrm{mg}$ once daily) was more effective than both the EU and North American doses of enoxaparin whilst maintaining comparable rates of major bleeding. However, in a meta-analysis of the pivotal studies comparing rivaroxaban with enoxaparin using standardized bleeding definitions for major, plus clinically relevant non-major, bleeding, rivaroxaban was associated with significantly higher rates of major bleeding plus clinically relevant non-major bleeding than enoxaparin. Apixaban $(2.5 \mathrm{mg}$ twice daily), also a factor $\mathrm{Xa}$ inhibitor, demonstrated superior efficacy and comparable safety compared with the EU dose of enoxaparin but was not as effective as the North American dose of enoxaparin. Dabigatran etexilate and rivaroxaban are currently the only new oral anticoagulant agents that are available for thromboprophylaxis following elective hip and knee replacement surgery. As there has been no head-to-head trial of these two agents, direct comparative data upon which to base clinical decisions are lacking. However, the choice of which oral anticoagulant agent to use in these surgical patients must be based on an assessment of each individual patient's risk factors for both VTE and bleeding, so that the chosen treatment ensures a balance between efficacy and safety.
Acknowledgements This work was supported by Boehringer Ingelheim. Writing and editorial assistance was provided by Louise Norbury and Rebecca Gardner, PhD of PAREXEL, which was contracted by Boehringer Ingelheim for these services. The author meets the criteria for authorship as recommended by the International Committee of Medical Journal Editors (ICMJE), was fully responsible for all content and editorial decisions and was involved at all stages of manuscript development. The author received no compensation related to the development of the manuscript.

Conflict of interest The author declares no conflict of interest.

Open Access This article is distributed under the terms of the Creative Commons Attribution Noncommercial License which permits any noncommercial use, distribution, and reproduction in any medium, provided the original author(s) and source are credited.

\section{References}

1. Geerts WH, Bergqvist D, Pineo GF, Heit JA, Samama CM, Lassen MR, Colwell CW, American College of Chest Physicians (2008) Prevention of venous thromboembolism: American College of Chest Physicians Evidence-Based Clinical Practice Guidelines (8th Edition). Chest 133(6 Suppl):381S-453S

2. Hirsh J, O'Donnell M, Eikelboom JW (2007) Beyond unfractionated heparin and warfarin: current and future advances. Circulation 116:552-560

3. Eikelboom JW, Weitz JI (2010) New anticoagulants. Circulation 121:1523-1532

4. Pradaxa ${ }^{\circledR}$ Summary of Product Characteristics (2009) Boehringer Ingelheim International $\mathrm{GmbH}$. http://emc.medicines.org.uk/medicine/ 20760. Accessed 10 June 2010

5. Eriksson BI, Dahl OE, Rosencher N, Kurth AA, van Dijk CN, Frostick SP, Prins MH, Hettiarachchi R, Hantel S, Schnee J, Büller HR (2007) Dabigatran etexilate versus enoxaparin for prevention of venous thromboembolism after total hip replacement: a randomised, double-blind, non-inferiority trial. Lancet 370:949-956

6. Eriksson BI, Dahl OE, Rosencher N, Kurth AA, van Dijk CN, Frostick SP, Kälebo P, Christiansen AV, Hantel S, Hettiarachchi R, Schnee J, Büller HR (2007) Oral dabigatran etexilate vs. subcutaneous enoxaparin for the prevention of venous thromboembolism after total knee replacement: the RE-MODEL randomized trial. J Thromb Haemost 5:2178-2185

7. Ginsberg JS, Davidson BL, Comp PC, Francis CW, Friedman RJ, Huo MH, Lieberman JR, Muntz JE, Raskob GE, Clements ML, Hantel S, Schnee JM, Caprini JA (2009) Oral thrombin inhibitor dabigatran etexilate vs North American enoxaparin regimen for prevention of venous thromboembolism after knee arthroplasty surgery. J Arthroplasty 24:1-9

8. Committee for Proprietary Medicinal Products (2000) Points to consider on clinical investigation of medicinal products for prophylaxis of intra- and post-operative venous thromboembolic risk. London: The European Agency for the Evaluation of Medicinal Products, 2000 Jun 29. Guideline no. CPMP/ EWP/707/98

9. Eriksson BI, Dahl OE, Huo MH et al (2011) Oral dabigatran versus enoxaparin for thromboprophylaxis after primary total hip arthroplasty (RE-NOVATE II). A randomised, double-blind, noninferiority trial. Thromb Haemost 105:721-729

10. Eriksson BI, Borris LC, Friedman RJ, Haas S, Huisman MV, Kakkar AK, Bandel TJ, Beckmann H, Muehlhofer E, Misselwitz 
F, Geerts W, RECORD1 Study Group (2008) Rivaroxaban versus enoxaparin for thromboprophylaxis after hip arthroplasty. N Engl J Med 358:2765-2775

11. Kakkar AK, Brenner B, Dahl OE, Eriksson BI, Mouret P, Muntz J, Soglian AG, Pap AF, Misselwitz F, Haas S, RECORD2 Investigators (2008) Extended duration rivaroxaban versus shortterm enoxaparin for the prevention of venous thromboembolism after total hip arthroplasty: a double-blind, randomised controlled trial. Lancet 372:31-39

12. Lassen MR, Ageno W, Borris LC, Lieberman JR, Rosencher $\mathrm{N}$, Bandel TJ, Misselwitz F, Turpie AG, RECORD3 Investigators (2008) Rivaroxaban versus enoxaparin for thromboprophylaxis after total knee arthroplasty. $N$ Engl J Med 358:2776-2786

13. Turpie AG, Lassen MR, Davidson BL, Bauer KA, Gent M, Kwong LM, Cushner FD, Lotke PA, Berkowitz SD, Bandel TJ, Benson A, Misselwitz F, Fisher WD, RECORD4 Investigators
(2009) Rivaroxaban versus enoxaparin for thromboprophylaxis after total knee arthroplasty (RECORD4): a randomised trial. Lancet 373:1673-1680

14. Eikelboom JW, Weitz JI (2008) Selective factor Xa inhibition for thromboprophylaxis. Lancet 372:6-8

15. Lassen MR, Raskob GE, Gallus A, Pineo G, Chen D, Portman RJ (2009) Apixaban or enoxaparin for thromboprophylaxis after knee replacement. N Engl J Med 361:594-604

16. Lassen MR, Raskob GE, Gallus A, Pineo G, Chen D, Hornick P (2010) Apixaban versus enoxaparin for thromboprophylaxis after knee replacement (ADVANCE-2): a randomised double-blind trial. Lancet 375:807-815

17. Huisman MV, Quinlan DJ, Dahl OE, Schulman S (2010) Enoxaparin versus dabigatran etexilate or rivaroxaban for thromboprophylaxis after hip or knee arthroplasty: results of separate pooled analyses of Phase III multicenter randomised trails. Circ Cardiovasc Qual Outcomes 3:652-660 